\title{
Anti-Wetting on Insect Cuticle - Structuring to Minimise Adhesion and Weight
}

\author{
Jolanta A. Watson ${ }^{1}$, Hsuan-Ming $\mathrm{Hu}^{1}$, \\ Bronwen W. Cribb² and Gregory S. Watson ${ }^{1}$ \\ ${ }^{1}$ James Cook University \\ ${ }^{2}$ The University of Queensland \\ Australia
}

\section{Introduction}

The next generation of non-contaminable and self-cleaning surfaces will require examination at all length scales in order to have enhanced abilities to control adhesion processes between surfaces. In particular, controlling adhesion between solids and liquids impacts on many aspects of life, from keeping surfaces clean to industrial applications such as the state-of-the-art of droplet-based micro-fluidics systems (Sun et al., 2005a; Yoshimitsu et al., 2002). Progress in the nanoelectromechanical systems and other nanotechnologies has prompted studies to reduce wearing inside micromechanical and nano-sized devices which will lead to improved functionalities and longer life expectancy (Burton \& Bhushan, 2005; Ando \& Ino, 1998; Mastrangelo, 1997; Abdelsalam et al., 2005). These improvements require new materials with low adhesion, friction and wettability which may be achieved by incorporating new structure designs on their surfaces. The ability to fabricate surfaces at two extremes - a surface that adheres to anything and a surface that nothing will adhere to would be the Holy Grail in regards to adhesion.

One of the most noteworthy naturally occurring nano-composite materials is the insect cuticle which, due to their surface micro- and nano-structures, have recently been shown to exhibit a range of impressive properties such as superhydrophobicity, self-cleaning technologies and directed wetting (Wagner, 1996; Cong et al., 2004; Gorb et al., 2000; Gao \& Jiang, 2004). These properties benefit insects with high wing surface area-to-body mass ratio (SA/M) and terrestrial insects (e.g., Holdgate, 1955; Wagner et al., 1996; Cong et al., 2004; Sun et al., 2005a; Gorb et al., 2000; Gao \& Jiang, 2004) that reside near water. Additional weight due to contamination can also potentially have a detrimental effect on the flight capabilities of these insects (Wagner et al., 1996). Thus, unlike many man-made anti-wetting materials, insect structuring is bound by weight and material constraints. In the worst case scenario the insect can become a victim of permanent immobilization on water or wetted surfaces with a reduced capacity to evade or fight off predators. To maintain their mobility and hence their capacity to avoid predation, these insects utilise hydrophobic chemistry and topographical structuring (Holdgate, 1955; Wagner et al., 1996) on their cuticles which reduce the contact with wetting surfaces and other adhesive contaminants.

Typical types of wing microarchitectures have evolved as a way of addressing insect survival allowing the insects to escape threatening environments. Adhesion to water and 
other adhesive surfaces such as spider webs can be prevented by cuticle hairs such as those found on the lacewing which appear to be an ancestral feature on insect wings (Masters \& Eisner, 1990). Other insects such as the damselfly utilise thousands of small stalk-like protuberances on the waxy wing membrane. Some cicadas have anti-reflective wing membrane resulting from surface nano-architectures which may also provide an ultra-low adhesion barrier to contaminating particles and water. Butterfly wing scales facilitate detachment from spider webs allowing the insect to break free. This scale architecture is also superhydrophobic due to distinct micro-structuring which in some cases is also responsible for particular optical characteristics such as colour (Parker \& Townley, 2007).

Two particular insect groups which have large wings and/or a high SA/M are the termite and cicada. In this study we examine the termites (Nasutitermes sp and Microcerotermes sp) and the black cicada (Gudanga sp. nr adamsi).

\section{Experimental method}

\subsection{Scanning electron microscopy}

Scanning electron microscope (SEM) imaging was undertaken using a square of dried wing tissue (approx. $3 \times 5 \mathrm{~mm}^{2}$ ) which was excised and mounted on aluminium pin-type stubs with carbon-impregnated double-sided adhesive, then sputter coated with 7-10 nm of platinum, before being imaged using a JEOL 6300 field emission SEM at $8 \mathrm{kV}$.

\subsection{Contact angle measurements}

A horizontal microscope (AIS-OPTICAL, model: AIS-V8G, magnification: 40X) with digital capturing (Panasonic Colour CCTV Camera, model: WV-CP410/G) of the images was used for precise measurements of static contact angles. As well, an XSP series compound microscope (York Instruments, Sydney, NSW, Australia) was utilised for optical microscopy. These were placed in a vertical, horizontal or inverted position to obtain top, side and bottom views, respectively. Magnifications of up to 40X were used.

Ten measurements per droplet were taken and images captured at ambient conditions of 20$25^{\circ} \mathrm{C}$ and $\mathrm{RH}$ of $60-75 \%$. Left and right angles between the sample surface and the tangent line to the droplet were considered as one measurement. Droplets of $10 \mu \mathrm{l}$ Milli-Q water were applied to the wing membranes. Smaller sized droplets were difficult to place on the superhydrophobic insect cuticle surfaces due to the adhesion between the water droplet and the syringe needle being stronger than the force of gravity and adhesion of the cuticle surface. Smaller water droplets were deposited via spraying utilising an atomiser.

\subsection{Photographic imaging}

Photographs of droplets resting on single excised wings were obtained using a Canon Digital 350D SLR and Canon Ultrasonic EF-S $60 \mathrm{~mm}$ macro lens at an 8 megapixel resolution. The photographs were cropped with no further image processing, and scale bars were applied using Photoshop.

\subsection{Replication process}

Negative replicas were produced by laying whole wings on liquid Epon araldite resin held in a silicone rubber mould. The resin was polymerised at $60^{\circ} \mathrm{C}$ for 3 days. After cooling, the wing tissue was pulled away from the resin leaving an impression that was used to produce a positive cast. 
The casts were then formed by the application of PolyDiMethylSiloxane (PDMS) (Sylgard ${ }^{\circledR}$ 184). PDMS was supplied by Dow Corning as a two part silicone elastomer. The base and curing agent were mixed at a 10:1 weight ratio, poured over the patterned resin and cured in an oven at $60^{\circ} \mathrm{C}$ for a sufficient amount of time to fully cure the polymer.

\section{Results and discussion}

\subsection{Topographical characterisation of insect wing cuticle}

The surfaces of the insect species studied in this investigation showed distinct differences in wing membrane structuring. The micro-nano structuring is characterised in table 1 listing the relevant geometrical parameters such as structure shape, spacing, depth, width and feature density (no of structures per unit area of membrane).

\begin{tabular}{|c|c|c|c|c|c|c|}
\hline Type/Species & Height & $\begin{array}{c}\text { Structure } \\
\text { density }\end{array}$ & $\begin{array}{c}\text { Structure } \\
\text { width }\end{array}$ & $\begin{array}{c}\text { Structure } \\
\text { spacing/ } \\
\text { periodicity }\end{array}$ & Shape & $\begin{array}{c}\text { Static } \\
\text { Contact } \\
\text { Angle }\end{array}$ \\
\hline $\begin{array}{c}\text { Termite } \\
\text { Nasutitermes } s p \\
\text { Microcerotermes }\end{array}$ & $\begin{array}{c}\text { Micrasters } \\
5-6 \mu \mathrm{m} \\
\text { Hairs } \\
\sim 70 \mu \mathrm{m}\end{array}$ & $\begin{array}{c}\text { Micrasters } \\
0.008 \text { per } \mu \mathrm{m}^{2} \\
\text { Hairs } \\
0.00015 \text { per } \\
\mu \mathrm{m}^{2}\end{array}$ & $\begin{array}{c}\text { Micrasters } \\
5-6 \mu \mathrm{m} \\
\text { Hairs at } \\
\text { base }<3 \\
\mu \mathrm{m}\end{array}$ & $\begin{array}{c}\text { Micrasters } \sim 10 \\
\mu \mathrm{m} \\
\text { centre-centre } \\
\text { dist.) } \\
\text { Hairs } \\
50-150 \mu \mathrm{m}\end{array}$ & $\begin{array}{c}\text { Micrasters } \\
\text { Star shaped } \\
\text { Hairs } \\
\text { Tapered } \\
\text { with } \\
\mu \text { channels }\end{array}$ & $\begin{array}{c}\text { Apparent } \\
\text { macro CA } \\
\text { on hairs and } \\
\text { micro CA on } \\
\text { micraster } \\
>170^{\circ}\end{array}$ \\
\hline $\begin{array}{c}\text { Black cicada } \\
\text { (Black region) } \\
\text { Gudanga sp. }\end{array}$ & $\begin{array}{c}\text { Forewing } \\
1.5 \mu \mathrm{m}\end{array}$ & $0.24 / \mu \mathrm{m}^{2}$ & $680 \mathrm{~nm}$ & $2.1 \mu \mathrm{m}$ & $\begin{array}{c}\text { Diamond- } \\
\text { like shape }\end{array}$ & $\sim 150^{\circ}$ \\
\hline $\begin{array}{c}\text { Black cicada } \\
\text { (Clear region) } \\
\text { Gudanga sp. }\end{array}$ & $200 \mathrm{~nm}$ & $42 / \mu \mathrm{m}^{2}$ & $80 \mathrm{~nm}$ & $200 \mathrm{~nm}$ & $\begin{array}{c}\text { Spherically } \\
\text { capped, } \\
\text { conical }\end{array}$ & $\sim 150^{\circ}$ \\
\hline
\end{tabular}

Table 1. Geometrical parameters of insect species investigated in this study.
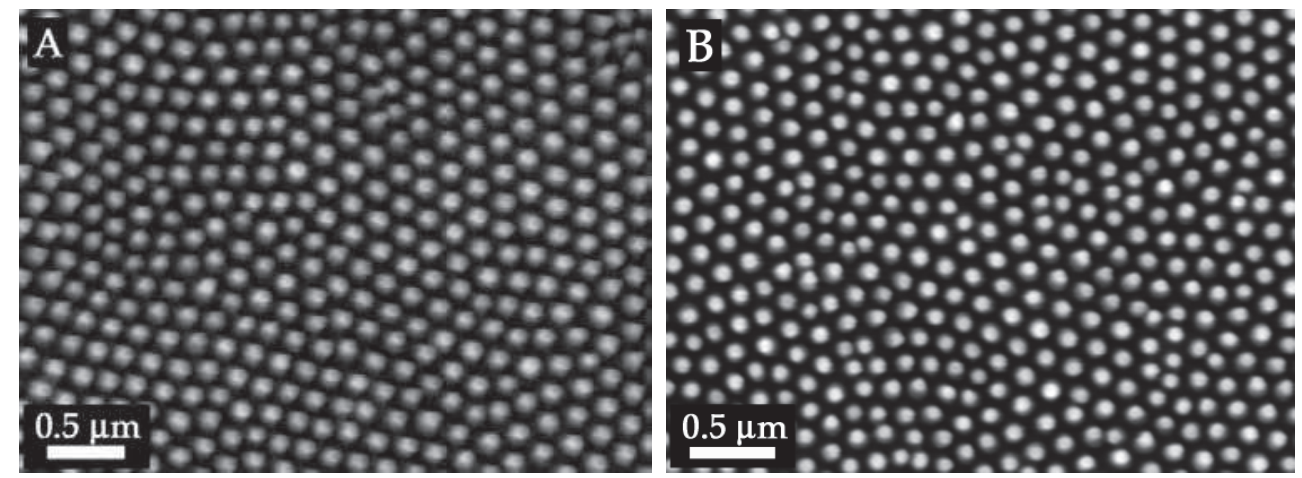

Fig. 1. A hexagonal, close-packed arrangement of conical protuberances on the wing membrane of the cicadas: (A) Cicadetta oldfieldii and, (B) Psaltoda claripenis.

Having coloured (black and red) and non-transparent wing regions, the wing of cicada species Gudanga sp. $n$ r adamsi (Black cicada) is in stark contrast to most cicada species which have completely transparent fore and hind wings. On most transparent cicada wings (e.g. 
Tamasa tristigma, Macrotristria angularis and Thopha saccata) the periodic array topography are all similar (Figure 1 (A) \& (B)) consisting of hexagonally packed spherically capped conical protuberances with a spacing and height of ca. $200 \mathrm{~nm}$ and radius of curvature of 25-45 $\mathrm{nm}$ at the apex. These structures are multifunctional, demonstrating anti-wetting properties and low adhesion with hydrophilic particles as well as an effective antireflective surface which presumably helps to camouflage the insect from predators.

The hind wing of the black cicada (Gudanga sp. nr adamsi) presents a region of intense red colour. Thus the cicada displays at rest or in flight two different colours (red and black). This colouration may aid the insect in camouflage. Camouflage involves background matching, disruptive colouration, or masquerading as an object other than an insect (Stevens \& Merilaita, 2009) (e.g., leaf-shaped wings/extremities of leaf insects (e.g., Phyllium giganteum), praying mantis species (e.g., Ameles decolour) and green or brown coloured wings and /or bodies (e.g., bladder cicada - Cystosoma saundersii)). Camouflage can be via a similarity in colour to a background, but often also incorporates a breaking up of the edge, since predators (vertebrates) have an enhanced capacity to see the edges of objects (probably an evolutionary strategy to obtain prey). Background matching usually deals with muted colours - browns, greys and blacks. So a black cicada would presumably be adapted for an environment of tree bark and leaf litter, whereas a red coloured cicada would stand out in such an environment. Disruptive colouration involves the use of patches of colour that are not the shape of the insect. This helps to break up the outline and thus hinder edge detection (e.g., large spots and lines on the wings of moths and butterflies and on bodies of caterpillars). However, most insects that use this approach present patterning that is in plain sight. In the case of the black cicada, the red is only shown during flight. In such circumstances the cicada will switch between being black and red during flight. This may require a predator to completely change its search image from one of shades and outlines, to one of colour and back again. There may be some disruptive effect too from a partial red wing breaking up its outline as it flies.

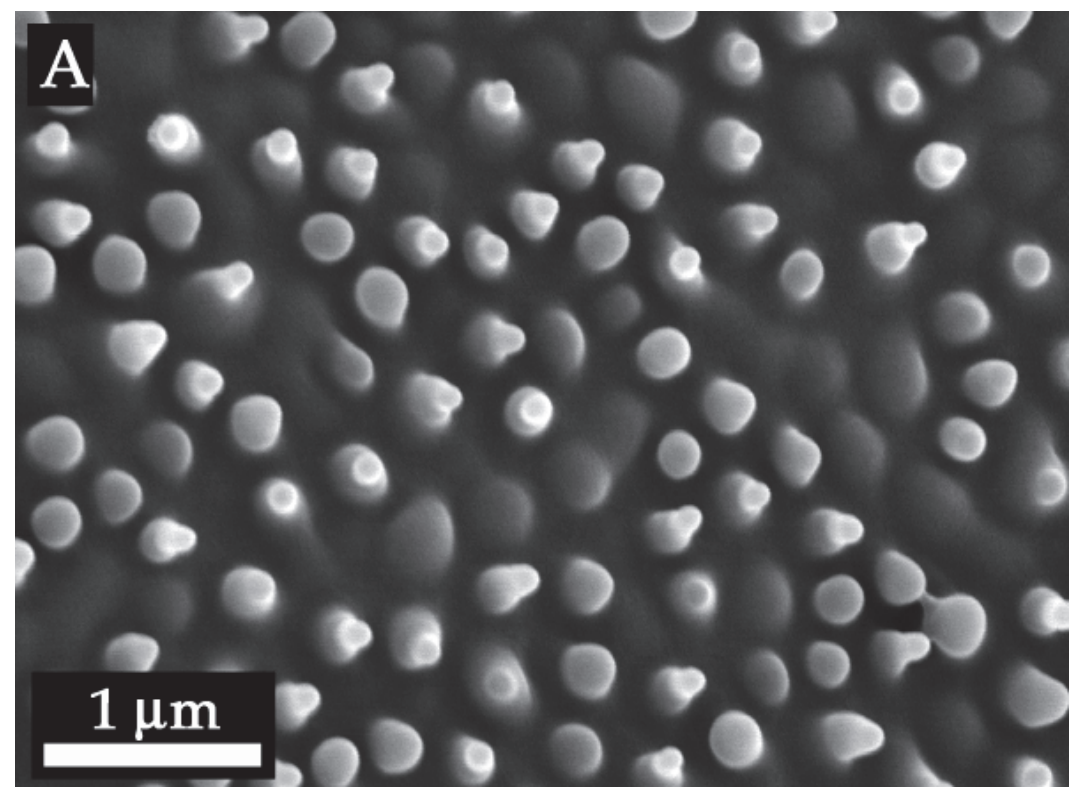



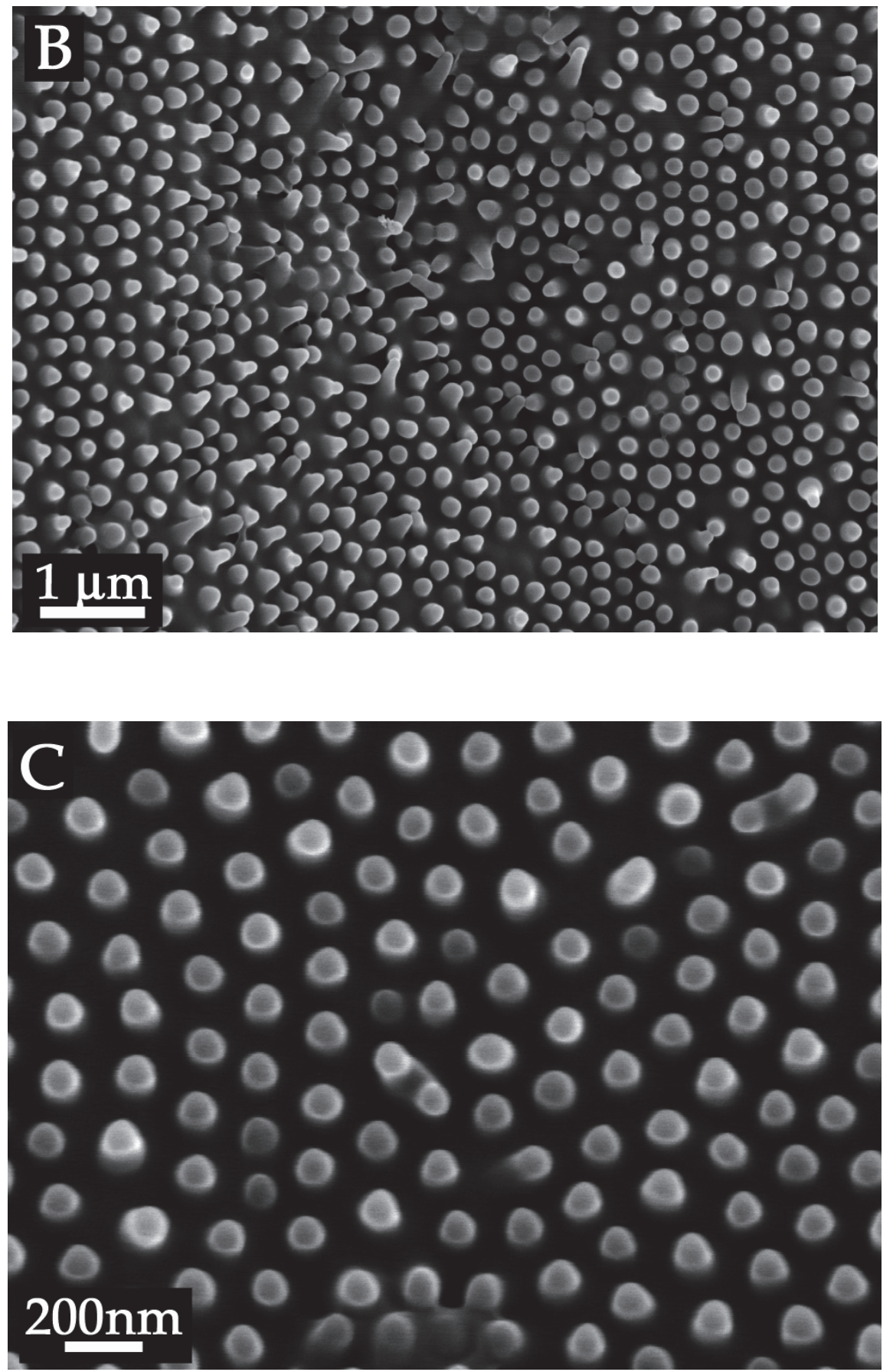

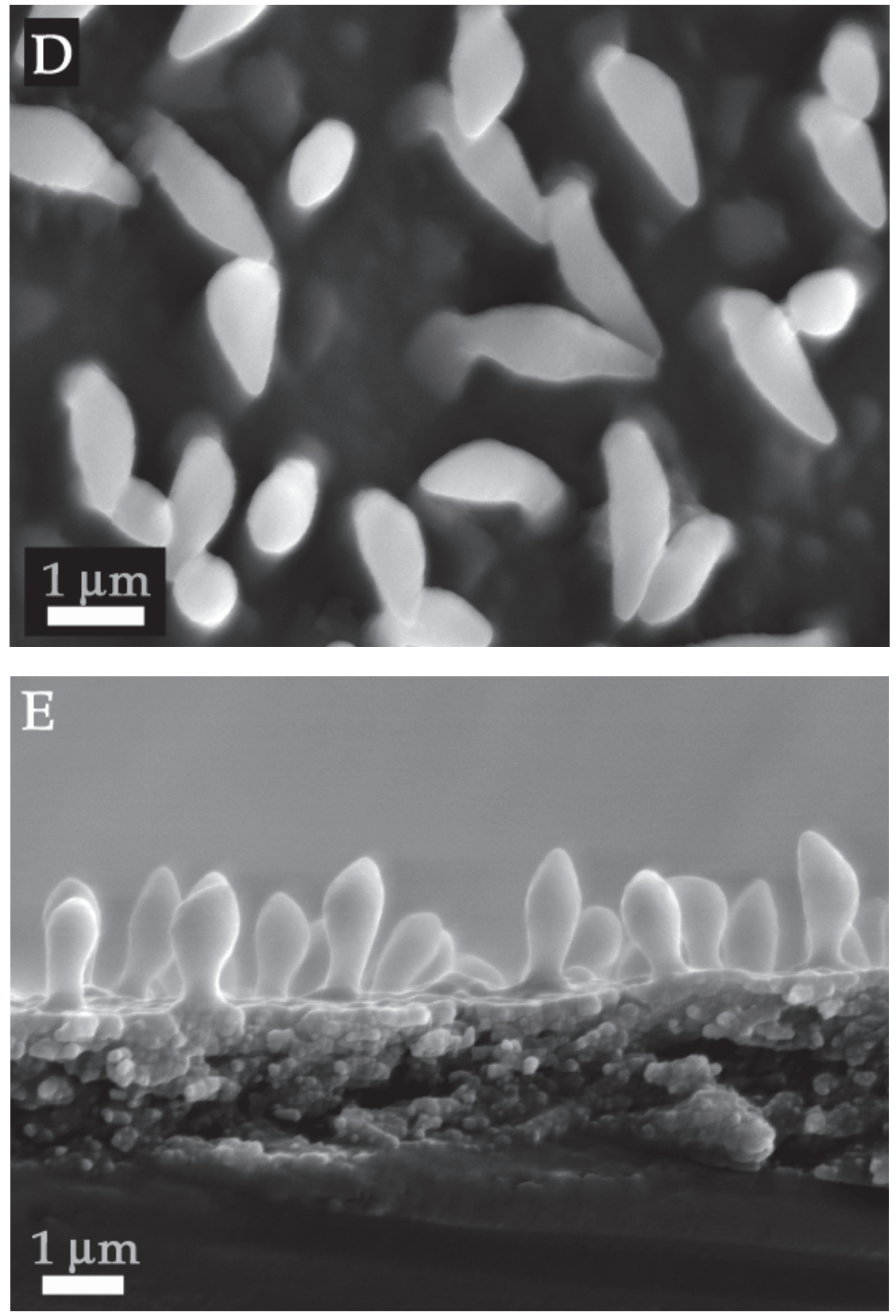

Fig. 2. SEM images of the black cicada (Gudanga sp. nr adamsi) wing membrane: (A) \& (B) red coloured region on the hind wing; (C) clear regions of wings; (D) Top view of the black coloured region on the forewing, and, (E) A cross-sectional view of the structures shown in (D). 
The intense red coloured regions on the hind wing of the black cicada comprised less ordered surface structures with many more 'defects' (figure 2 (A) \& (B)) than the typical transparent regions found on the transparent sections of the wing (figure 2 (C)). Interestingly, the non-transparent coloured part of the forewing (black in colour) showed a dramatically different structuring. It comprised of a less ordered surface with individual diamond shaped structures almost one order of magnitude larger in height and (maximum) width (figure 2 (D) \& (E)). This provides strong evidence for specific dimensional structure size/shape for specific functionality on selected regions of the wings. Regions of the wing where the antireflection property is required have the necessary structure dimensions (less than the wavelength of light), while other coloured regions are not restricted by this wavelength condition.

Both the transparent and coloured sections of the cicada wing membrane demonstrated superhydrophobic surfaces with static contact angles close to or above $150^{\circ}$. There are a number of theories to express the superhydrophobic condition all of which have certain assumptions and limitations (Cassie \& Baxter, 1944; Wenzel, 1936; Gao \& McCarthy, 2007, Wang \& Jiang, 2007). Two common but different theories purport to describe the effect on hydrophobicity of surface roughness. The theory by Wenzel (1936) makes the assumption that, when a liquid drop is placed on a surface consisting of protrusions, the liquid will fill the open spaces, as shown in figure 3 (A). This model predicts that roughness of the surface reinforces both hydrophobicity and hydrophilicity. Cassie and Baxter (1944), on the other hand, consider the microstructures to be a heterogeneous surface composed of solid and air. The crucial assumption is that the spaces around the asperities will remain filled with air with the droplet resting on top of the surface as shown in figure 3 (B).
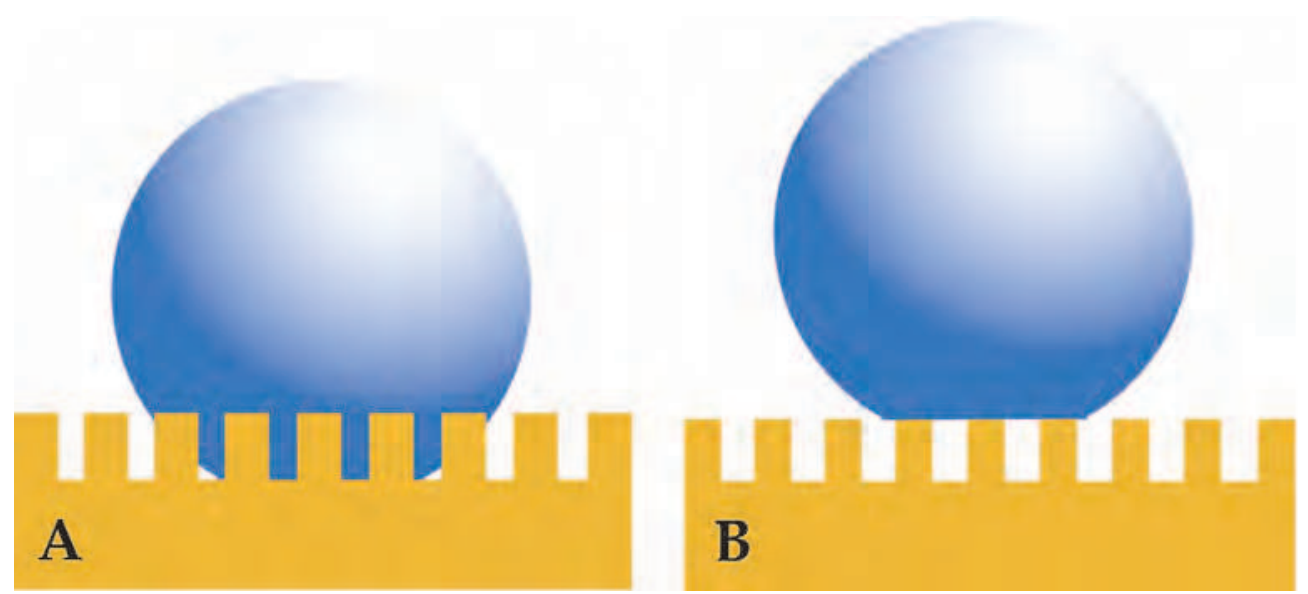

Fig. 3. A diagrammatic representation of the Wenzel Model (A) whereby the water droplet penetrates the protuberances down to the surface, and Cassie-Baxter Model (B) which assumes the water droplet retains its shape whilst perched on top of the structures.

The Cassie-Baxter and Wenzel models describe static droplets at equilibrium, and allow calculation of the contact angle for the two conditions. For an array of hemispherical-top protrusions the corresponding equations for the contact angle are: 


$$
\begin{gathered}
\cos \theta_{C}=-1+\phi_{B}\left(\cos \theta_{\Upsilon}+1\right)^{2} \\
\cos \theta_{W}=\left[1+4 \phi_{S}\left(\frac{h}{d}-0.25\right)\right] \cos \theta_{\Upsilon}
\end{gathered}
$$

where $\phi_{B}$ is the ratio of the basal area of the protrusion over the total area, $\phi_{S}$ is the solid fraction of protrusions with $\phi_{S}=\left(\pi d^{2}\right) /\left(4 l^{2}\right), d$ is the diameter of the base of the protrusions, $h$ is the structure height, and $l$ is the center-to-center pitch (nearest-neighbour spacing for an ordered array). $\theta_{Y}$ is the ideal contact angle of water on a smooth surface of identical chemistry $\left(\theta_{Y}=105^{\circ}\right.$ is an appropriate estimate in the present case (e.g., (Gao \& Jiang, 2004; Feng et al., 2007; Tong et al., 2005)). Cassie and Baxter express the superhydrophobic state in terms of a number of interfaces; a liquid-air interface with the ambient environment surrounding the droplet and a surface under the droplet involving solid-air, solid-liquid and liquid-air interfaces. Equation 1 necessitates the surface to have the required roughness to allow air in topographically favoured regions such as troughs and surface depressions. Thus topographies which increase the air-water interface and minimise the solid-liquid contact area will lead to higher contact angles.

Using the Cassie-Baxter model to describe the array of hemispherical-top protrusions (a close approximation to the structures shown in figure 2 (A) \& (B) for the black cicada) from equation 1 we determine a predicted contact angle for the cicada membrane on transparent and nonregions are $153^{\circ}$. This value correlates well with the experimentally determined value. The transparent regions of the wing membranes are forced to compromise the geometrical structure parameters due to the antireflection constraint as mentioned above. Even so, the membrane still manages to achieve superhydrophobic contact angles. The superhydrophobic contact angles demonstrate a self-cleaning surface which may aid in maintaining the efficiency of the anti-reflective coating. A recent study of fabricated superhydrophobic nanostructures with comparative spacing and height to the cicada arrays reported measured values of contact angle similar to our results (Nosonovsky \& Bhushan, 2008).

The non-transparent black regions of the cicada wing cuticle of Gudanga sp. nr adamsi also present structuring which satisfy a number of the above contact conditions. The diamondlike shape additionally demonstrates 'design' features for material minimisation (allowing reduced weight) while also lowering the solid-liquid contact area and allowing a larger pocket/volume of air to occupy the volume beneath the water droplet. If the diamond-like structures were similar in shape to the smaller nanostructuring on the wings (the $200 \mathrm{~nm}$ features - conical, spherically capped) then the structures would comprise protuberances with a significant increase in weight (more than $30 \%$ ).

The spacing between individual diamond structures as seen in figure 2 (D) and (E) are generally less than $5 \mu \mathrm{m}$ indicating that this may be near a critical distance for structures of these heights (several $\mu \mathrm{m}$ ) interacting with water. Indeed a study on fabricated surfaces shows that larger spacings can be more susceptible to wetting (Jung \& Bhushan, 2007; Bhushan \& Jung, 2008). The cicada membrane must be resistant to water under a variety of conditions so as not to make contact with the underlying surface or promote a transition to the fully wetted state. Liu \& Lange (2006) have shown that on a surface with spherical protrusions it is unfavourable for the contact line of water to advance beyond halfway down the structure at the point where the meniscus will start to be stretched. Thus the diamond 
structuring found on the black cicada may aid to prevent further penetration of water droplets towards the wing membrane (i.e., prevents liquids fully wetting the wing). The diamond structuring may also be multifunctional, providing similar attributes as some butterflies e.g., camouflage display, signalling, thermo-regulation control (e.g., Wong et al., 1997; Parker \& Townley, 2007).

The above features suggest that the black cicada may represent ideal micro/nano structures for replication. Attempts to replicate the features however proved difficult using the wing as a 'natural template' due to the diamond-like shape of the structuring. Figure 4 (A) shows the resulting polymer replica. The replicated features only formed to a height of several hundred nanometres. However, structures of similar dimensions (height and spacing) to Gudanga sp can be found on other wings of coloured cicada species (Gaeana cheni and Tosena sybilla). The Gaeana cheni cicada wing membrane has two coloured regions on its wings: a yellow region and a brown region. The SEM images of the yellow (figure 4 (B)) and brown (figure $4(\mathrm{C})$ ) coloured regions (cross-sectional SEM images are shown in the insets) show a height and width difference of ca. $110 \mathrm{~nm}$ and ca. $300 \mathrm{~nm}$, respectively. Figure 4 (D) shows an SEM image of the polymer replica produced from the wing structuring of Gaeana cheni. The wing membrane structuring and a PDMS replica of the cicada Tosena sybilla are shown in the SEM images in figure $4(\mathrm{E}) \&(\mathrm{~F})$, respectively. The replicated structures are $\sim 2 \mu \mathrm{m}$ in height and $\sim 2 \mu \mathrm{m}$ in spacing. Figure $4(\mathrm{G}) \&(\mathrm{H})$ demonstrate the contact behaviour of water droplets on one of the polymer replicates and for comparison, a flat polydimethylsiloxane (PDMS) sample is also shown. PDMS is a commonly used hydrophobic polymer with a measured contact angle of ca. $101-105^{\circ}$ (Sun et al., 2005b) in good agreement with figure $4(\mathrm{H})$. Droplets on the replicated surfaces showed superhydrophobic contact angles. Even PDMS replicated structure heights approximately half the height of Gudanga sp (produced from Gaeana cheni $750 \mathrm{~nm}$ ) produced superhydrophobic interactions. The images in figure 4 illustrate the increased hydrophobicity when roughness is introduced to the polymer surface at these dimensions.

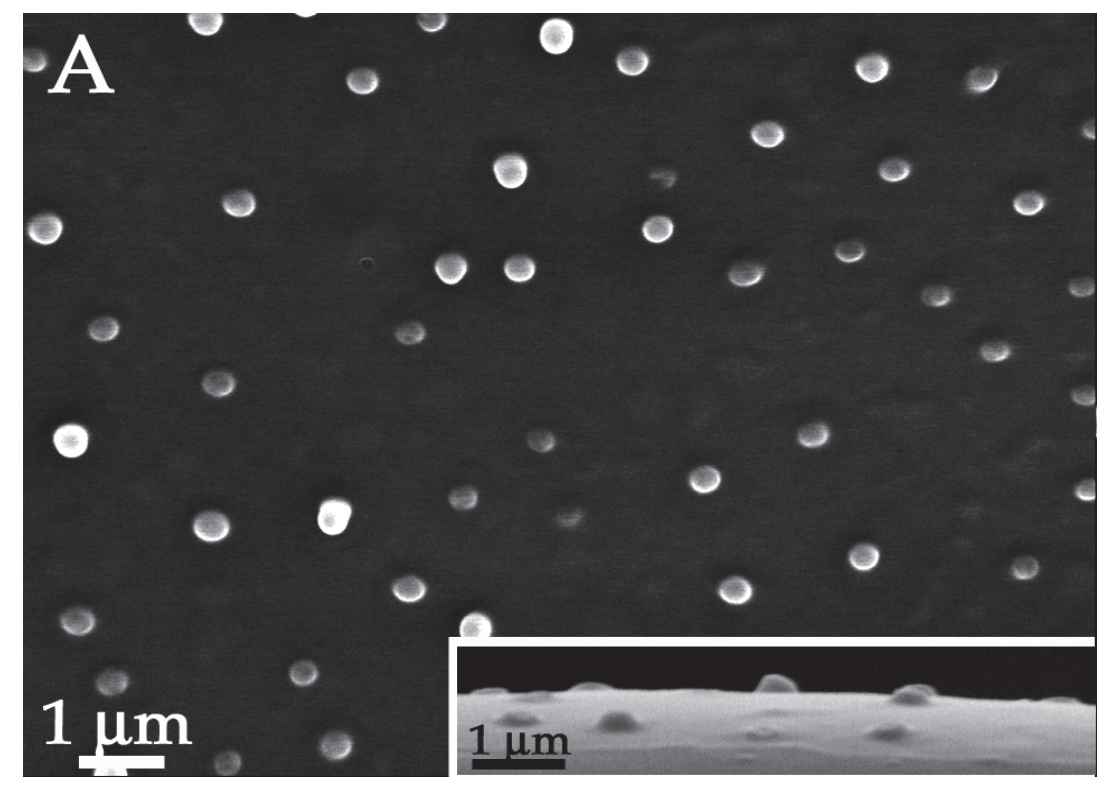



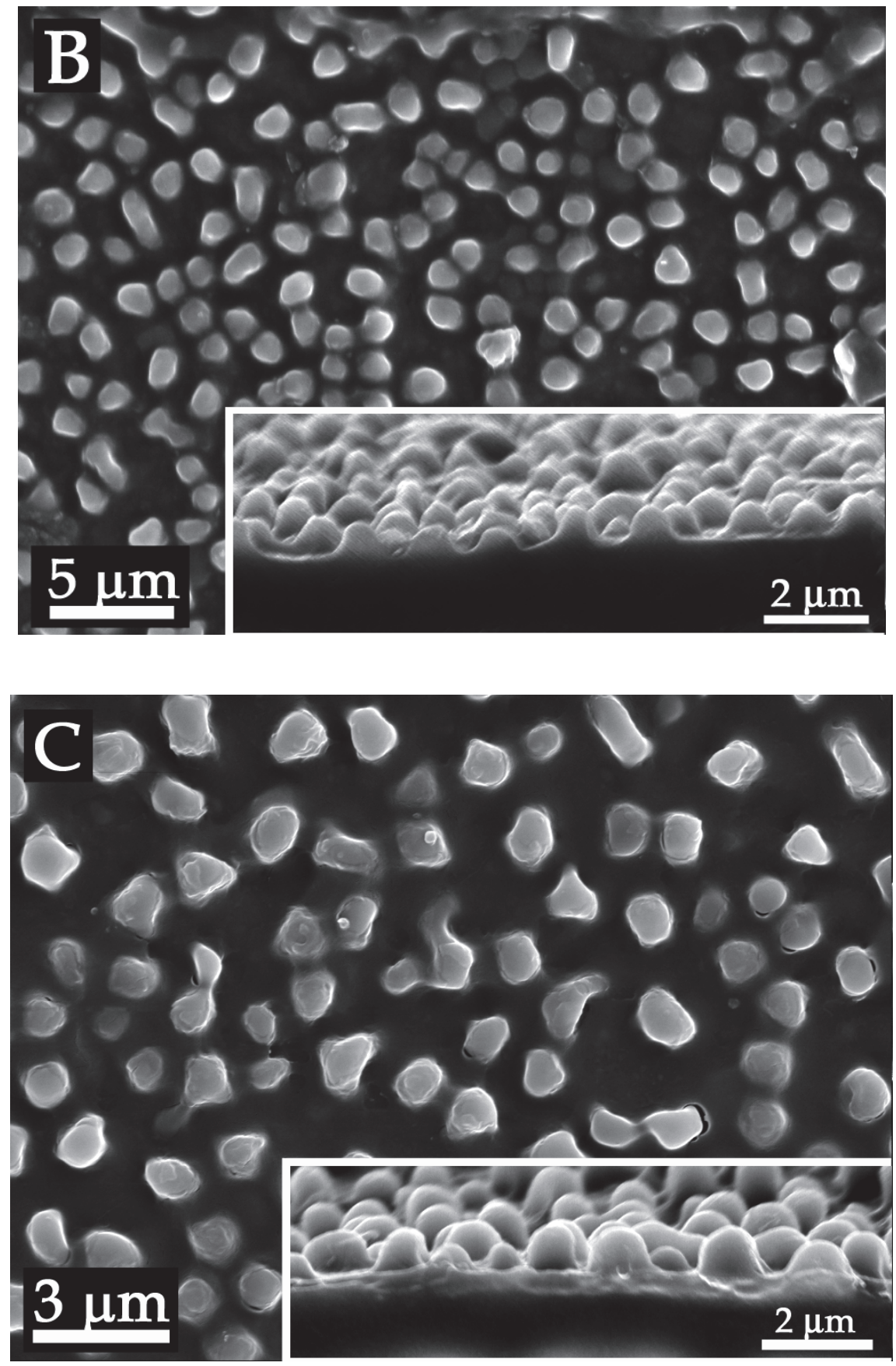

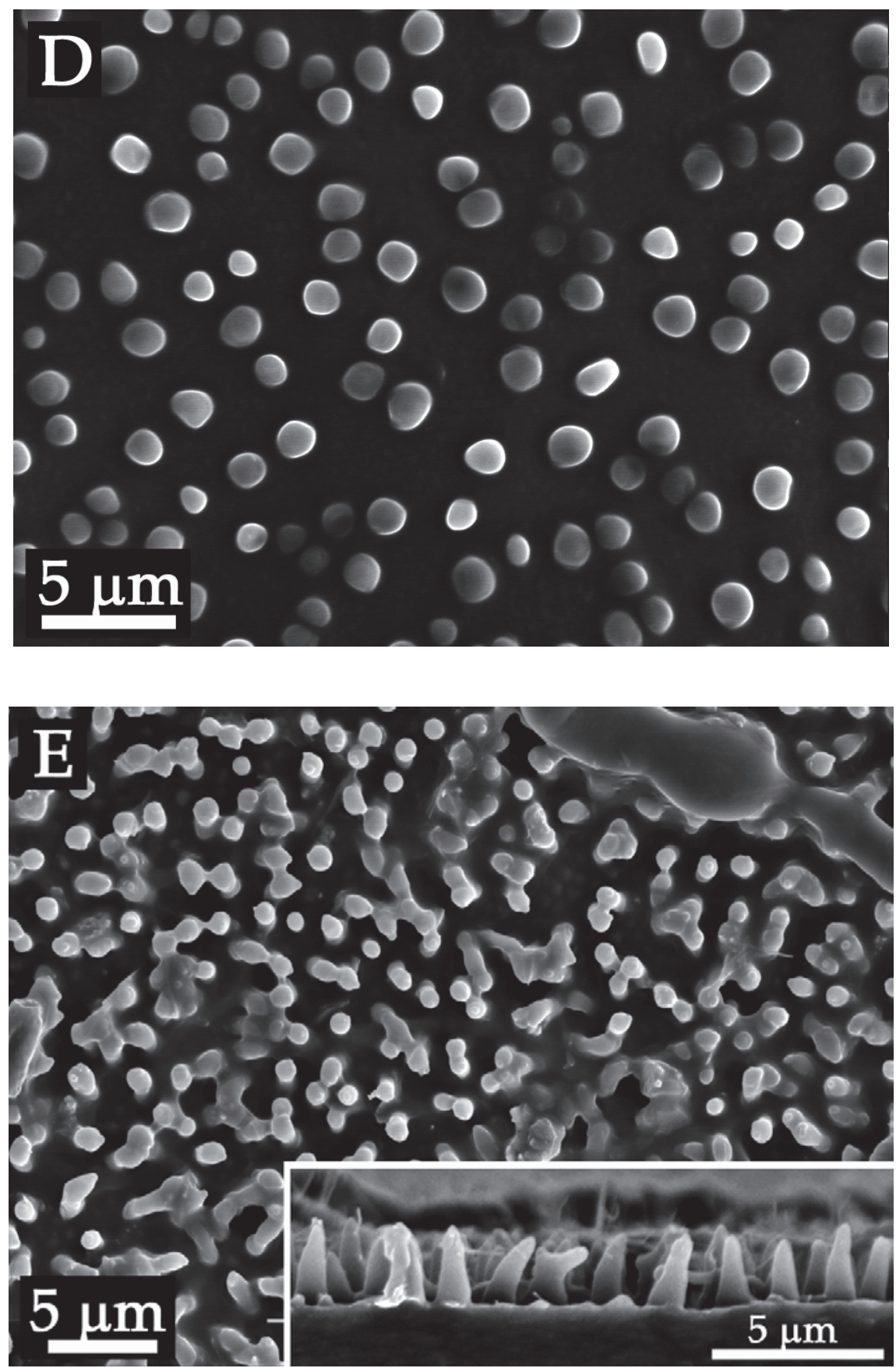

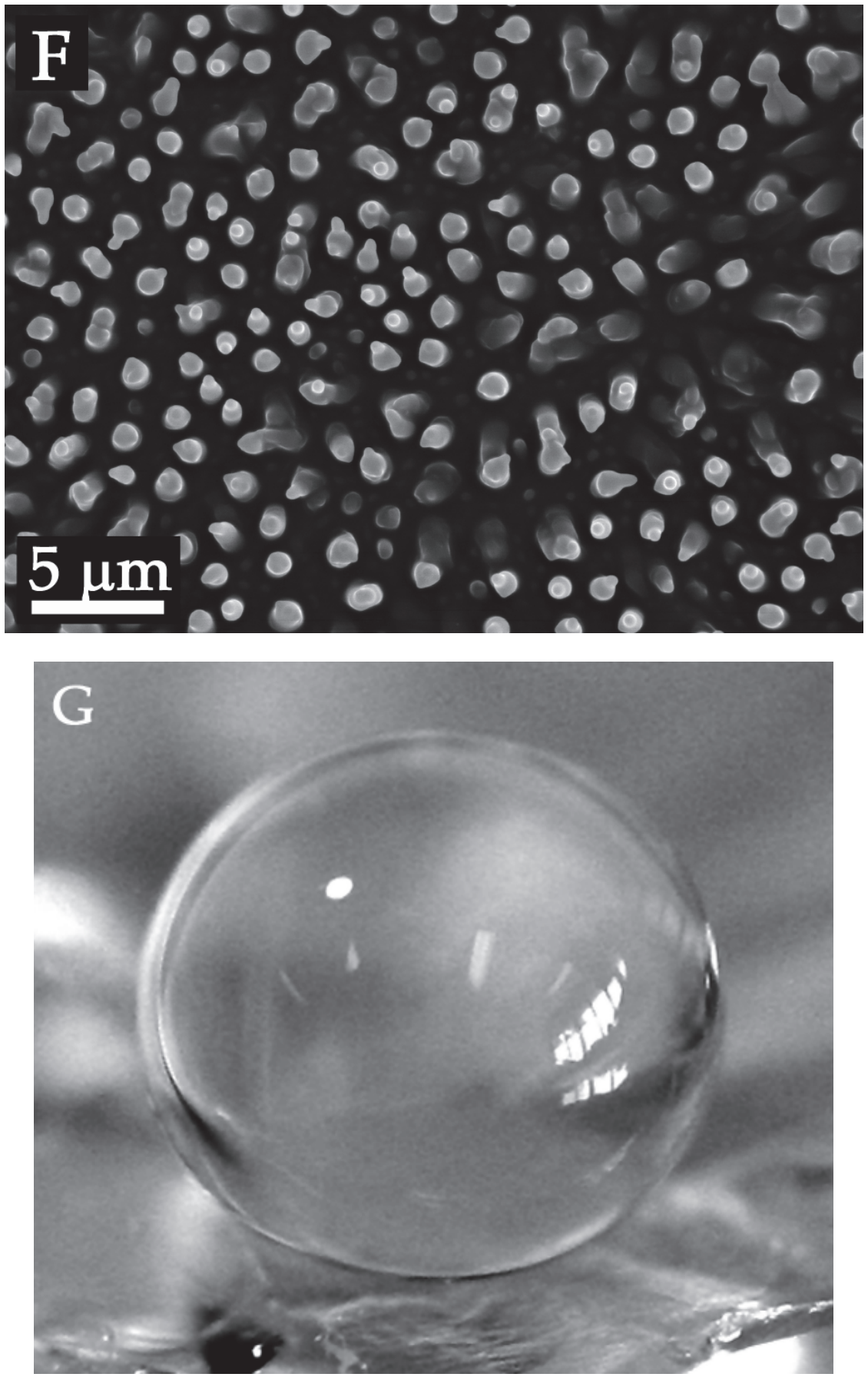


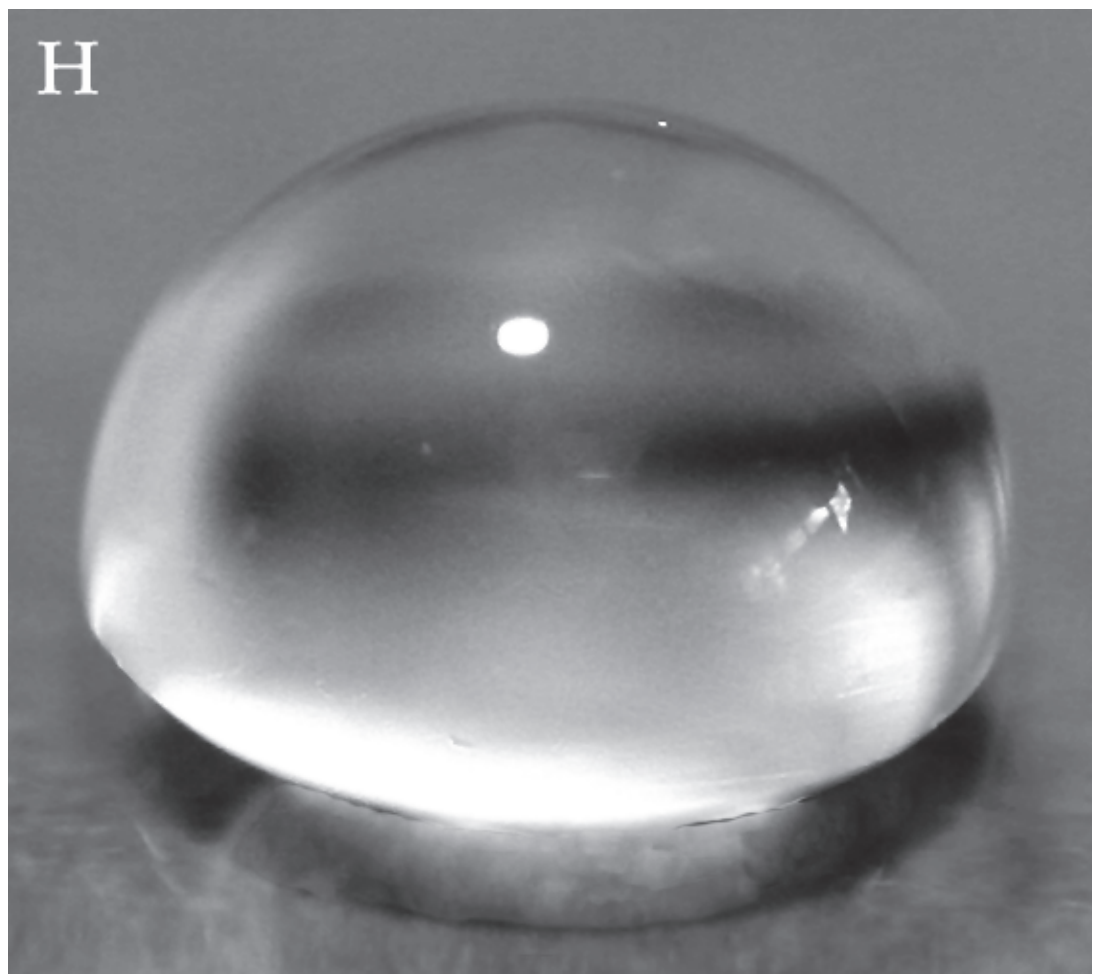

Fig. 4. SEM images of: (A) Black Cicada replica (inset shows a cross-sectional view); (B) Yellow region on Gaeana cheni; (C) Brown region on Gaeana cheni; (D) PDMS replica of Gaeana cheni; (E) Coloured region on Tosena sybilla; and, (F) PDMS replica of this region of Tosena sybilla. Photographs showing a $10 \mu \mathrm{l}$ droplet deposited on a PDMS Gaeana cheni replica $(G)$, and a PDMS surface with no structuring $(\mathrm{H})$.

The other insects investigated in this study are two species of termites. Typically very weak fliers with an extremely high SA/M value in relation to many other insect species, termites (previously Order Isoptera (Inward et al., 2007)) that fly from the nest during rain periods (The Insects of Aust., 1991) require specialised hydrophobic structures on their wings to optimise the chances of the colonisation flight. The flying duration is generally short but critical in the establishment of new colonies (The Insects of Aust, 1991). The termites presumably fly during rain periods where a mobile canvas of moving droplets decreases the likelihood of predator attack and ensures water will be present when establishing a new colony.

Optical photography demonstrating the interaction of small droplets of water with the wing membrane on two different termites (Nasutitermes $s p$ and Microcerotermes $s p$ ) is shown in figure 5 (A) and (B), respectively. The droplets exhibit remarkable apparent contact angles (CA) of $180^{\circ}$ with the underlying membrane. The droplets were then examined using an optical microscope. Droplets were also deposited onto the wing membranes via a pressure sprayer which formed small micro-droplets. Figure 5 (C) shows a high resolution optical microscope image of a water droplet (from Figure 5 (A)) on the wing of Nasutitermes sp. The 
image was obtained whilst viewing through the droplet from above. The water droplet is being held up above the membrane wing surface by the macrotrichia (hairs) near centre of droplet. This is evidenced by the dimpling effect when the macrotrichia are compressed beneath the weight of the water droplet (three examples highlighted by the arrows). Not all of the wing hairs directly beneath the water droplet are in contact. This is due to the fact that the hairs are inclined with the surface at slightly different angles however under higher loads more hairs will be in contact. Figure 5 (D) shows a lower resolution optical microscope image demonstrating different sized droplets' spherical shape whilst being held up by the macrotrichia.
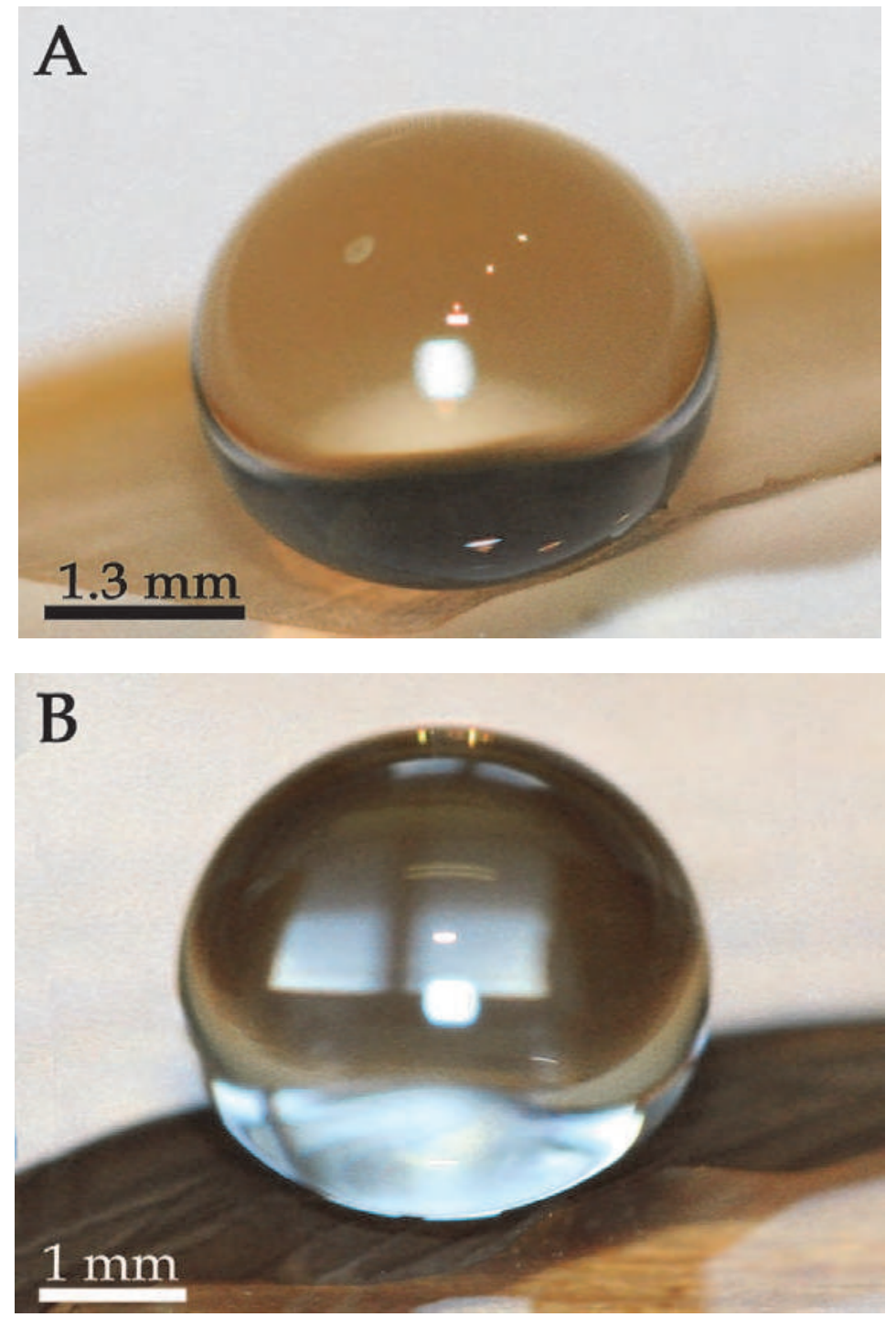

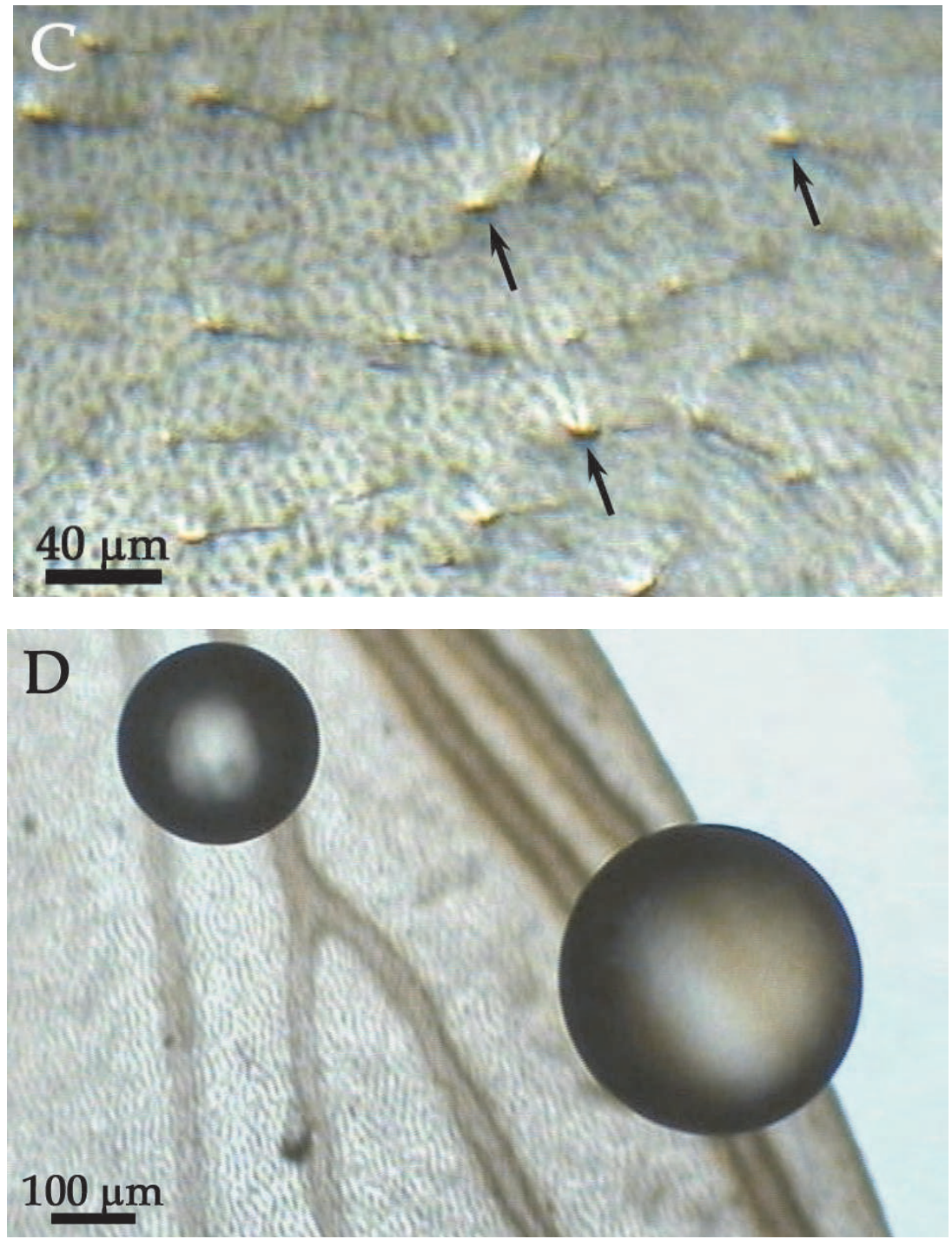

Fig. 5. (A) and (B) Optical photographs showing suspension of water droplets above the wing surface membranes of the termite species (A) Nasutitermes sp and (B) Microcerotermes $s p$. (C) An optical microscope image (viewing through the droplet from above) of a water droplet being held up by the hairs (macrotrichia) from the membrane wing surface on Nasutitermes sp. (near centre of droplet). Not all of the wing hairs directly beneath the water droplet are in contact. The dimpling effect resulting from the indentation of the water surface by the hairs is evident (three examples highlighted by the arrows). The hairs are inclined with the surface at slightly different angles. (D) A lower resolution optical microscope image demonstrating the droplets' spherical shape whilst being held up by the macrotrichia. 
Without artificially creating a region of lower potential energy on an isolated termite wing laid on a flat supporting surface (i.e., create a well/dip in the middle of the wing membrane), it is extremely difficult to place a stable water droplet. The anisotropic forces exerted by the hairs seem to be one of the contributing factors for the spontaneous removal of water from the termite wing. Figure 5 (C) shows the droplet weight is supported by the many membrane macrotrichia (figure $5(\mathrm{C})$ ). The macrotrichia act as a series of springs with a restoring force which balances the weight of the droplet above the membrane. As a result, the droplet is highly unstable, particularly in the lateral direction. When a loading force is applied to the droplets shown in figure 5 (A) and (B) (e.g., by micro syringe pressure) the droplet is forced to move closer to the membrane surface, however, when the loading force is removed the hair arrays spring back and return the droplet to the original position above the surface.

As with other insect cuticular structures, hairs on insects have been shown to serve multifunctional purposes such as protection against wetting, minimising contact with solid surfaces and aerodynamic factors (e.g., Gorb, 2001; Marden \& Kramer, 1994; Masters \& Eisner, 1990).

Figure 6 (A) and (B) show SEM images revealing the arrangement of the hairs on the termite wing membrane yielding many thousands of hairs per single wing surface. For both termite species, this relatively low density of the hairs, combined with a number of open troughs running along the long axis of the shaft of each hair from the base to near the tip, provide an elegant way to resist water while minimising the weight. Indeed the very low density of hairs adds no significant weight to the wing membrane. Yet as little as 100 hairs can support the weight of a $10 \mu \mathrm{l}$ droplet with minor hair deflections of less than $10 \mu \mathrm{m}$. The open troughs of the hairs with channel edges of 50-150 $\mathrm{nm}$ radius of curvature will reduce the contact area made with solid and liquid bodies. This type of nano-structuring is also evident with some semi-aquatic insects such as the water strider which has many thousands of hairs (setae) on each leg. These contribute toward the ability to resist penetration into water bodies (droplets and bulk water).

As well as the hair structuring, distributed on the wing membrane are micrasters (starshaped structures) which are a skeletal framework comprised of 5-7 distinct arms consisting of uniformly thin sheets around $90-120 \mathrm{~nm}$ in width (figure 6). Many of the sheets originate from the same central location on the star structure and have a secondary nano-roughness on the top ridges (see figure 6 (B)). Their highest point is typically 5-6 $\mu \mathrm{m}$ tall and their width (extremity of arm to arm distance) is generally 5-6 $\mu \mathrm{m}$. The centre to centre spacing of the structures is $\sim 10 \mu \mathrm{m}$.

The micrasters have been previously reported but their function/s had remained a mystery (Roonwal, 1985; Rathore, 1977; Rathore, 1974). In order to investigate this further, micrasters were interacted with micro-droplets of water which were sprayed onto the wing surface. A high resolution optical microscope image (Figure 7 (A)) shows that only minimal contacts are made on a number of the micraster apex. This allows the droplets to maintain their spherical shape and reduce adhesion. Droplets transform from the Cassie-Baxter state to the Wenzel state (see figure 7 (B)) when they evaporate to smaller dimensions. Close examination shows that the droplets are connected to the substrate via meniscus bridging which is unstable and increases in area over time as observed under optical microscopy. Droplets of similar volumes were sprayed onto a glass microscope slide and a hydrophobic PDMS surface for comparison (figure 7 (C) \& (D), respectively). 

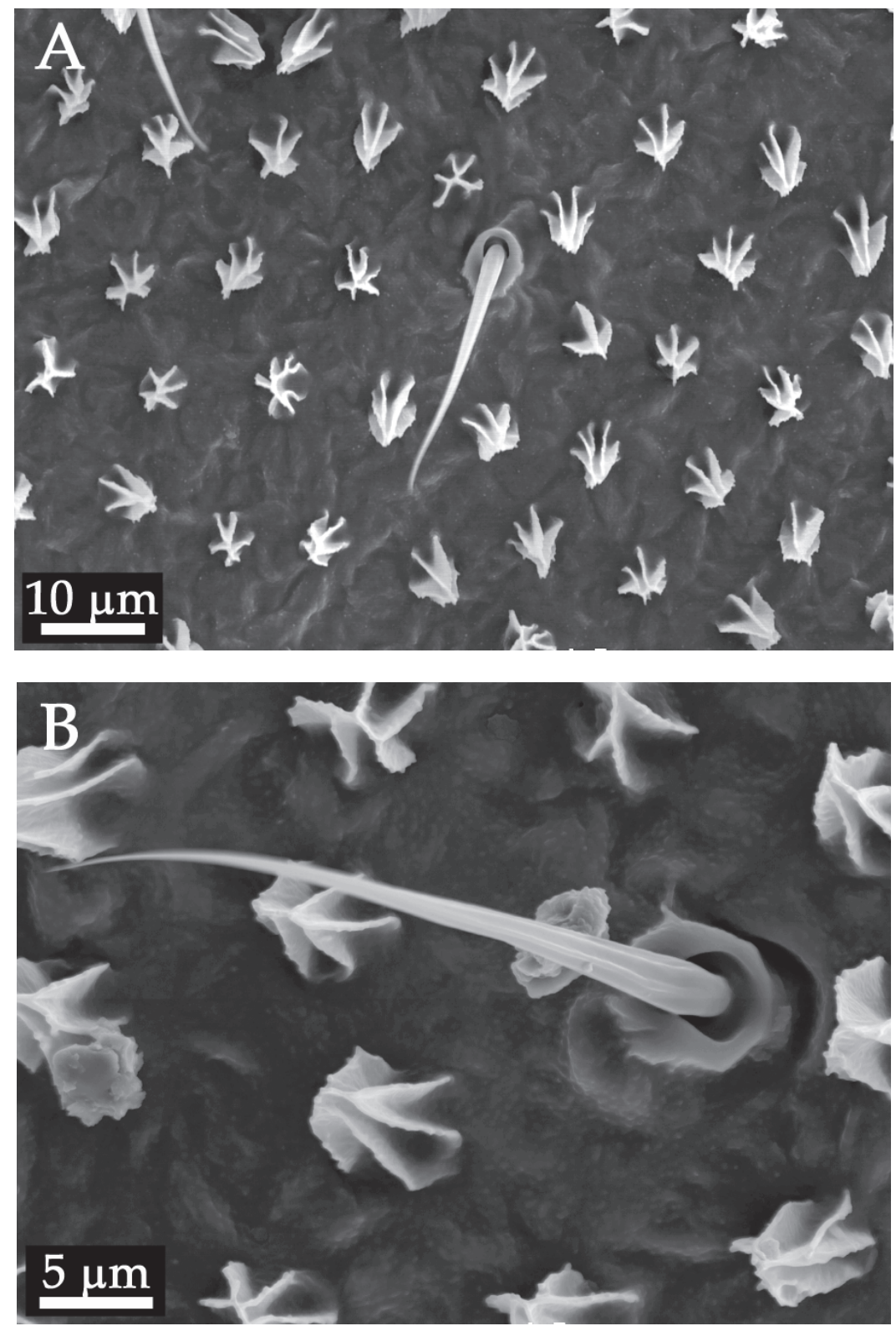

Fig. 6. (A) An SEM topographical landscape showing macrotrichia in sockets and starshaped structures (micrasters) evenly spaced on the wing surface of Microcerotermes sp. (B) Higher resolution SEM image showing the hair and micraster fine structure. The hair and micrasters both exhibit a sheet-like structuring. The result is a series of troughs aligned along the long axis on the hairs while the micrasters exhibit an open framework with radiating arms. 


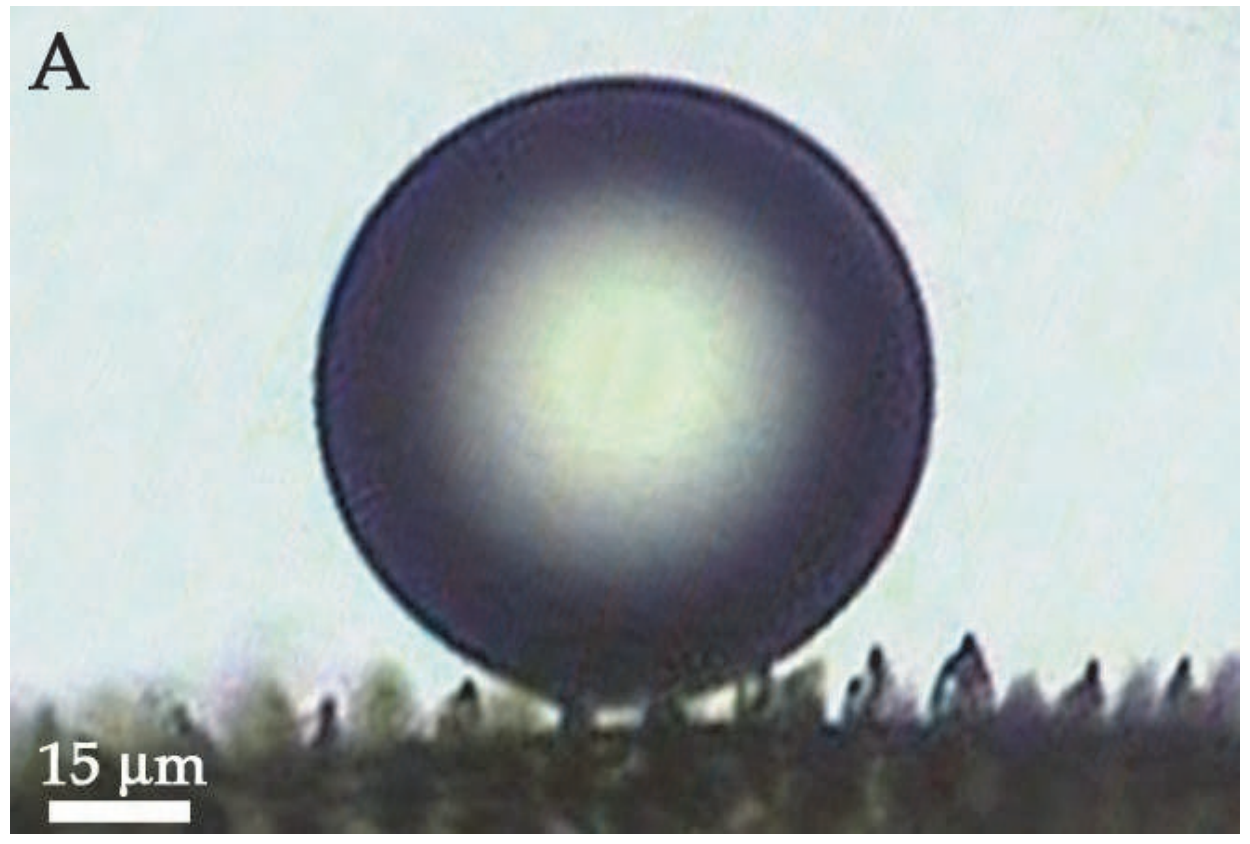

\section{B}

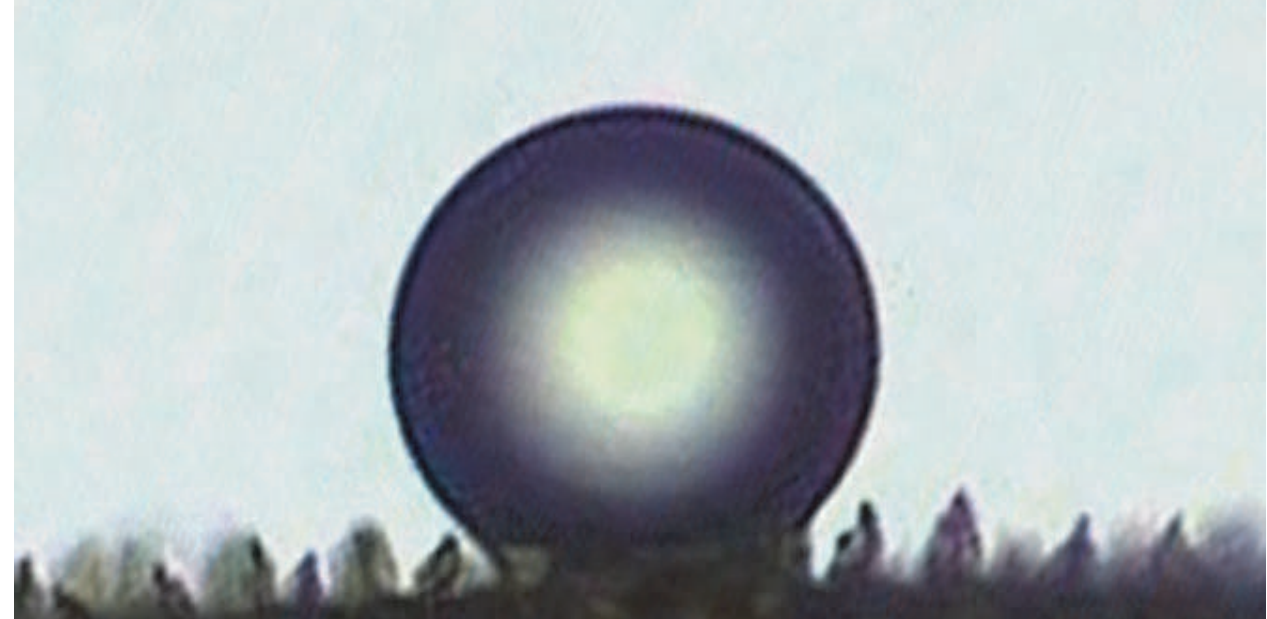

\section{$15 \mu \mathrm{m}$}



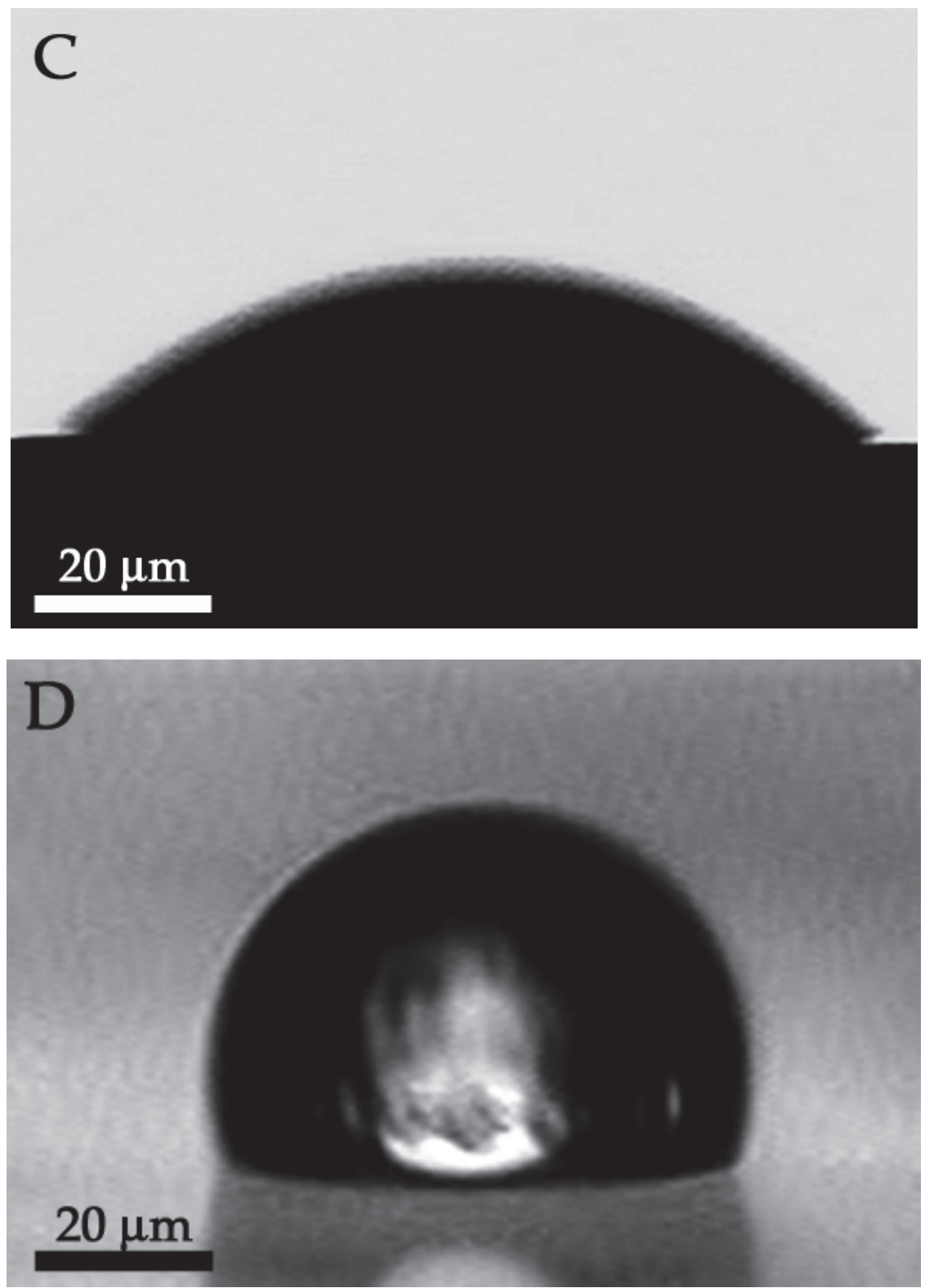

Fig. 7. Interaction of a small micro-sized water droplet with a number of different surfaces. (A) A micro droplet on the termite wing membrane of Microcerotermes sp. As the droplet evaporates it changes from the Cassie regime to the Wenzel state (B). For comparison, droplets of similar volumes were also sprayed onto a hydrophilic glass microscope slide and a hydrophobic PDMS surface (C) and (D), respectively. 
With in excess of one million of these micrasters per wing, approximating the micrasters as parabolic shaped sheet structures (a close approximation) having material density ranges at the lower end of insect cuticular material $\left(1 \mathrm{~g} \mathrm{~cm}^{-3}\right)$ (Lockey, 1960; Neville \& Parry, 1976), the additional weight in relation to the total insect weight would only be $3.2 \%$ on Nasutitermes $s p$ and $7.3 \%$ on Microcerotermes sp. If, however, the micrasters were not sheet-like but solid micro structures, such as in the cicada structuring, then the increase in weight would be significant. If we make this approximation, then using solid parabolic 3-dimensional domes (a solid fraction represented by a volume with a membrane enclosing the skeletal sheet framework), the constituted weight increase would become approximately $37 \%$ of the total body mass of Nasutitermes sp and $84 \%$ of Microcerotermes sp; (almost the same weight as that of the insect itself).

Not bounded by weight and material constraints, solid structures of similar dimensions, both natural and man-made, have demonstrated antiwetting and superhydrophobic properties (Sun et al., 2005a; Sun et al., 2005b; Ma \& Hill, 2006; Nosonovsky \& Bhushan, 2008). Minimising the amount of material and weight required by a significant amount, the skeletal sheet-like structure arrangement provides an integral component of the anti-wetting hierarchical shielding of the termite allowing them to fly in wet conditions without adverse weight effects. Reducing weight by flying with minimal water content the termite alates (winged termites) typically have large quantities of stored nutrients. They do however rehydrate during the initial stages of colony foundation (The Insects of Aust, 1991; Nalepa et al., 2001).

Observations viewed by optical microscopy showed that micro droplets were removed from the membrane surface by at least four mechanisms:

1. Micro-droplets are mobilised by minor vibrations/movements of the wings facilitated by minimal adhesion with the micrasters.

2. Contact of micro-droplets with other micro-droplets promotes mobilisation.

3. Larger droplets resting on the hairs absorb micro-droplets resting on the micrasters.

4. Constant wetting allows micro droplets to build-up in size and are then large enough for removal via the hair arrays.

Droplets as small as $100 \mu \mathrm{m}$ can be held above the wing surface by the hairs. The termite will typically encounter droplet conditions when active during storm and wet conditions (The Insects of Aust, 1991). Indeed, both species used in this study were collected during flight in the rain (5 separate occasions). This demonstrates that the insects can easily cope with rain where flight has to be maintained. As termites are not typically good fliers and have a low wing flapping rate, the 'shedding efficiency' of water on the surface, and thus interaction time with droplets may be critical to maintaining controlled flight.

A PDMS replica of the termite hierarchical structuring is shown in figure 8. Both the micraster and hair structuring can be replicated with a high degree of detail.

Figure 9 shows diagrammatically the anti-wetting scaffolding arrangement on the termite wing (A) and both the diamond shaped structures on the black cicada wing (B), and dome shaped anti-reflective structures of the clear regions of the wings (C). The specialised topographies are designed for minimising the solid-liquid contact area and maximising the liquid-air contact. The hair/micraster array demonstrates an elegant hierarchical designed arranged approach for minimising interaction with water bodies of various length scales. As well, the open membrane hierarchy demonstrates a configuration for achieving this state utilising minimal structural material and thus reduced weight for the insect. The diamondlike structuring also presents anti-wetting patterning with minimal material and density. 


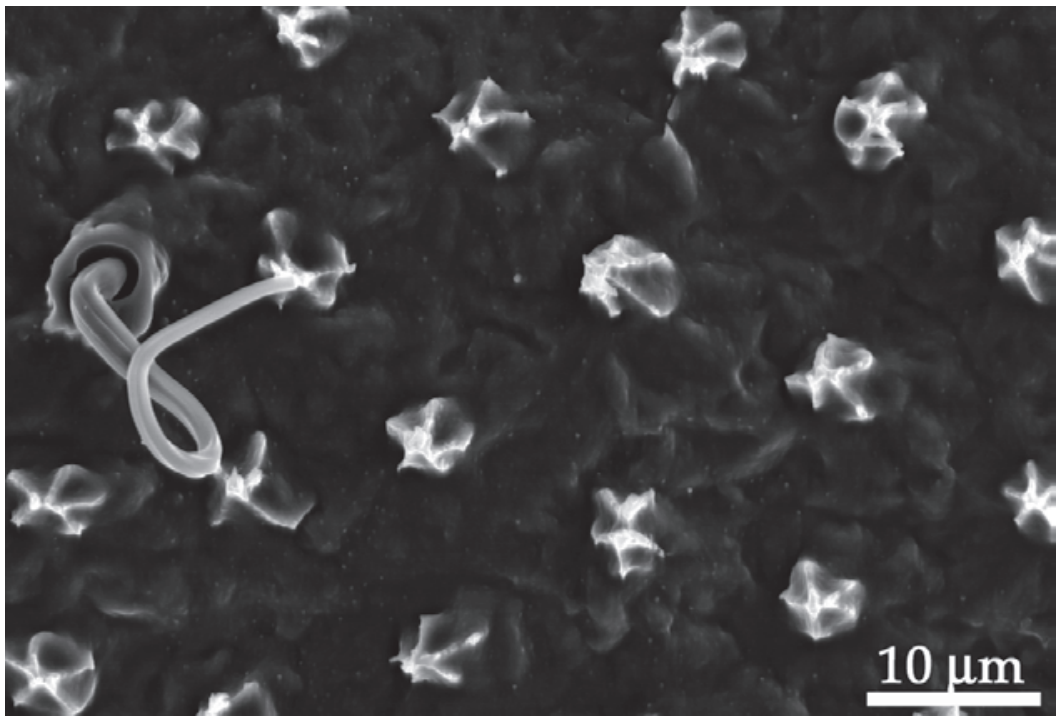

Fig. 8. An SEM image of a PDMS replica of the wing membrane of Microcerotermes sp.
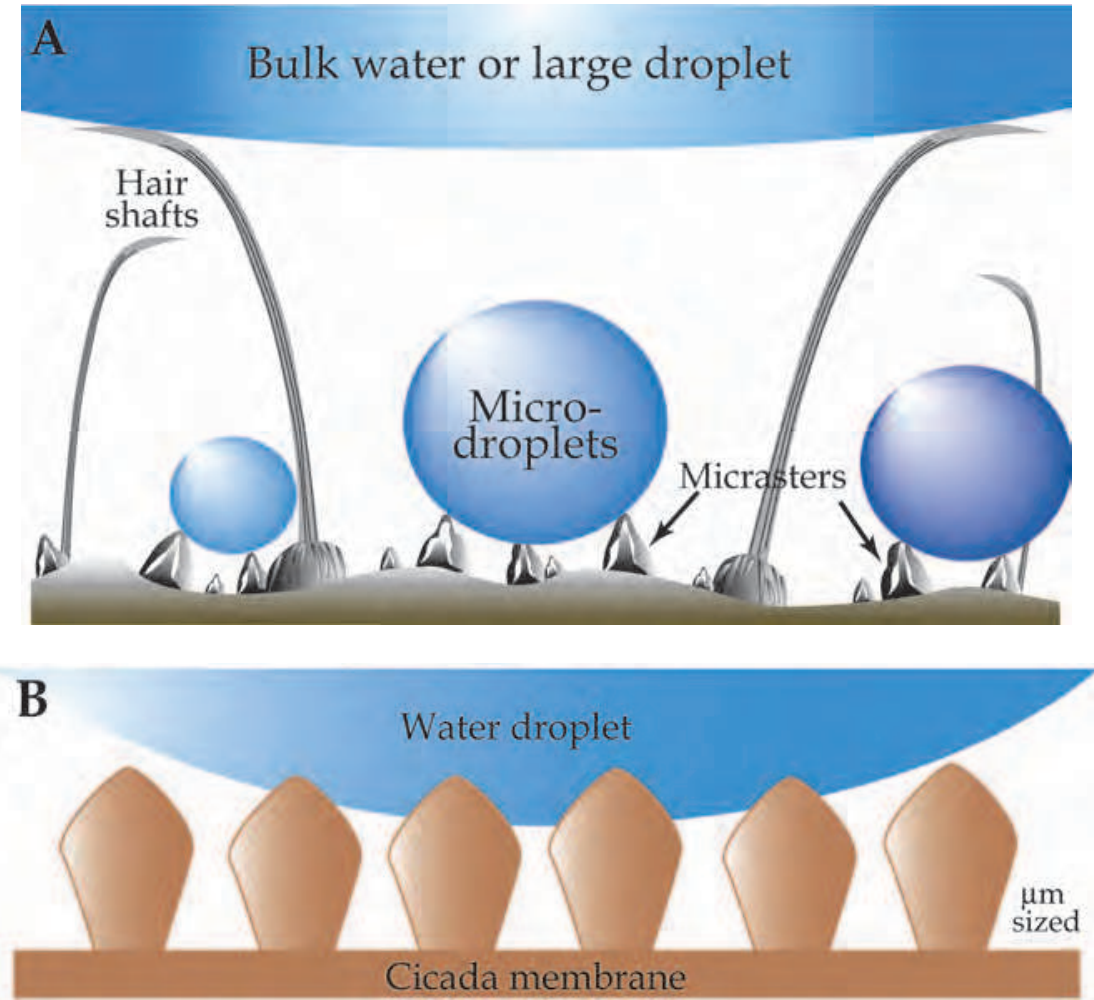


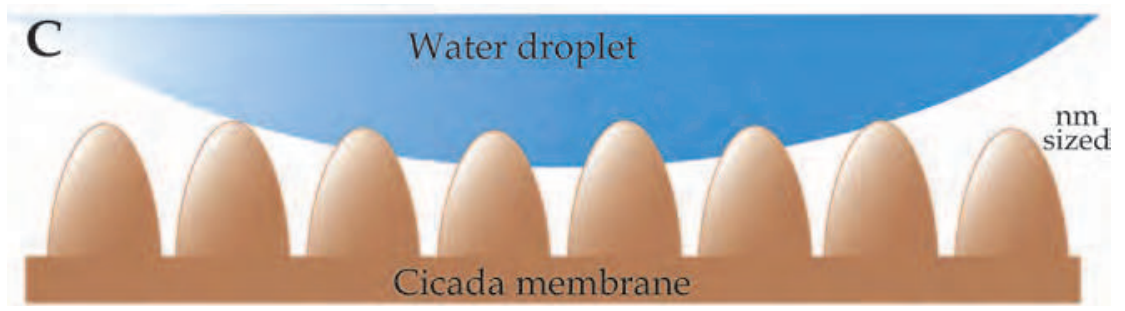

Fig. 9. Diagrammatic representation of the hierarchical structuring on the termite wing (A) showing macrotrichia and micrasters designed to minimise interaction with water bodies of various sizes. The open sheet architecture on both hair and micraster aides in weight reduction. (B) Diagrammatic representation of the micron sized diamond-shaped structuring on the black cicada wing (B), and the more common nanostructuring found on transparent regions of the cicada wings (C) showing the two size regimes for achieving superhydrophobicity.

\section{Conclusion}

Additional weight as a consequence of contact of water with wings can potentially have a detrimental effect on the flight capabilities of some insects. A reduction in mobility can also significantly reduce the ability to escape predators. In the worst case scenario the insect can become immobilized on water or wetted surfaces (ponds, foliage, gravel). Insects with a high wing surface area to body mass ratio will be especially susceptible to these effects. Typically insects address this problem by having a wing cuticle which is hydrophobic or super hydrophobic. However, unlike many man-made anti-wetting materials insect structuring is bound by weight and material constraints. In this study we have shown how three different insect species (cicada and termite) satisfy the conditions of weight minimisation and anti-wetting. In the case of hairy winged insects such as the termite a hierarchical approach to the problem is utilised. The cicada on the other hand compromises wing structuring to facilitate a number of conditions or functions (e.g., antireflective/antiwetting structuring). In this case there is strong evidence for specific dimensional structure size/shape for specific functionality on selected regions of the wings. The diamond shape structuring presents an interesting pathway to reduce mass and resources. The designs and structuring of the insect wings provide examples of technologies available freely from nature which can potentially be utilised to contribute to the next generation of bio-inspired materials and devices. Thus replication of this structuring may aid in control of fluidic flow, adhesion and wetting properties at the macro and micro/nano scales where weight considerations need to be taken into account.

\section{Acknowledgment}

The authors would like to thank Dr. Sverre Myhra for fruitful discussions.

\section{References}

Abdelsalam, M. E.; Bartlett, P. N.; Kelf, T. \& Baumberg, J. (2005). Wetting of Regularly Structured Gold Surfaces. Langmuir, Vol. 21, No. 5, (January 2005), pp. 1753-1757, ISSN: 0743-7463 
Ando, Y. \& Ino, J. (1998). Friction and Pull-off Forces on Submicron-size Asperities. Wear, Vol. 216, No. 2, (April 1998), pp. 115 -122, ISSN: 0043-1648

Bhushan, B. \& Jung, Y. C. (2008). Wetting, Adhesion and Friction of Superhydrophobic and Hydrophilic Leaves and Fabricated Micro/Nanopatterned Surfaces. Journal of Physics: Condensed Matter, Vol. 20, No. 22, (June 2008), 225010 (24 pp), ISSN 09538984

Burton, Z. \& Bhushan, B. (2005). Hydrophobicity, Adhesion, and Friction Properties of Nanopatterned Polymers and Scale Dependence for Micro- and Nanoelectromechanical Systems. NanoLetters, Vol. 5, No. 8, (July 2005), pp. 1607 1613, ISSN: 1530-6984

Cassie, A. B. D. \& Baxter, S. (1944). Wettability of Porous Surfaces. Transactions of the Faraday Society, Vol. 49, (June 1944), pp. 546-551.

Cong, Q.; Chen, G-H.; Fang, Y. \& Ren, L-Q. (2004). Study on the Super-Hydrophobic Characteristic of Butterfly Wing Surface. Journal of Bionic Engineering, Vol. 1, pp. 249-255, ISSN: 1672-6529

Feng, X-Q.; Gao, X.; Wu, Z.; Jiang, L. \& Zheng, Q-S. (2007). Superior Water Repellency of Water Strider Legs with Hierarchical Structures: Experiments and Analysis. Langmuir, Vol. 23, No. 9, (March 2007), pp. 4892-4896. ISSN: 0743-7463

Gao, X. \& Jiang, L. (2004). Water-Repellent Legs of Water Striders. Nature, Vol. 432, No. 7013, (November 2004), p. 36, ISSN: 0028-0836

Gao, L. \& McCarthy, T. J. (2007). How Wenzel and Cassie Were Wrong, Langmuir, Vol. 23, No. 7, (February 2007), pp. 3762-3765. ISSN: 0743-7463

Gorb, S. N.; Kesel, A. \& Berger, J. (2000). Microsculpture of the Wing Surface in Odonata: Evidence for Cuticular Wax Covering. Arthropod Structure \& Development, Vol. 29, No. 2, (April 2000), pp. 129-135, ISSN: 1467-8039

Gorb, S. (2001). Attachment Devices of Insect Cuticle, Kluwer Academic Publishers, ISBN: 07923-7153-4, The Netherlands, pp. 21-36.

Holdgate, M. W. (1955). The Wetting of Insect Cuticles by Water. Journal of Experimental Biology. Vol. 32, No. 3, (September 1955), pp. 591-617, ISSN: 0022-0949

The Insects of Australia: A Textbook for students and research workers. (1991). Melbourne University Press, ISBN: 0-522-84454-5, Australia, Vol. 1.

Inward, D.; Beccaloni, G. \& Eggleton, P. (2007). Death of an Order: A Comprehensive Molecular Phylogenetic Study Confirms That Termites are Eusocial Cockroaches. Biology Letters, Vol. 3, No. 3, (June 2007), pp. 331-335, ISSN: 1744-957X

Jung, Y. C. \& Bhushan, B. (2007). Wetting Transition of Water Droplets on Superhydrophobic Patterned Surfaces, Scripta Materialia, Vol. 57, No. 12, (December 2007), pp. 1057-1060, ISSN: 1359-6462

Liu, B. \& Lange, F.F. (2006). Pressure Induced Transition Between Superhydrophobic States: Configuration Diagrams and Effect of Surface Feature Size, Journal of Colloid and Interface Science, Vol. 298, No. 2, (June 2006), pp. 899-909, ISSN: 0021-9797

Lockey, K. H. (1960). The Thickness of Some Insect Epicuticular Wax Layers. Journal of Experimental Biology, Vol. 37, No. 2, (June 1960), pp. 316-329, ISSN: 0022-0949

Ma, M. \& Hill, R. M. (2006). Superhydrophobic Surfaces. Current Opinion in Colloid and Interface Science. Vol. 11, No. 4, (October 2006), pp. 193-202, ISSN: 1359-0294

Marden, J. H. \& Kramer, M. G. (1994). Surface-Skimming Stoneflies: A Possible Intermediate Stage in Insect Flight Evolution. Science, Vol. 266, No. 5184, (October 1994), pp. 427430, ISSN 0036-8075

Masters, W. M. \& Eisner, T. (1990). The Escape Strategy of Green Lacewings from Orb Webs. Journal of Insect Behaviour, Vol. 3, No. 2, (March 1990), pp. 143-157, ISSN: 0892-7553 
Mastrangelo, C. H. (1997). Adhesion-Related Failure Mechanisms in Micromechanical Devices. Tribology Letters, Vol. 3, No. 3, (September 1997), pp. 223-238, ISSN: 1023-8883

Nalepa, C. A.; Miller, L. R. \& Lenz, M. (2001). Flight Characteristics of Mastotermes darwiniensis (Isoptera, Mastotermitidae). Insectes Sociaux, Vol. 48, No. 2, (June 2001), pp. 144-148, ISSN: 0020-1812

Neville, A. C.; Parry, D. A. D. \& Woodhead-Galloway, J. (1976). The Chitin Crystallite in Arthropod Cuticle. Journal of Cell Science, Vol. 21, No. 1, pp. 73-82, ISSN 0021-9533

Nosonovsky, M. \& Bhushan, B. (2008). Biologically Inspired Surfaces: Broadening the Scope of Roughness. Advanced Functional Materials, Vol. 18, No. 6, (March 2008), pp. 843855, ISSN: $1616-3028$

Parker, A. R. \& Townley, H. E. (2007). Biomimetics of Photonic Nanostructures. Nature Nanotechnology, Vol. 2, No. 6, (June 2006), pp. 347-353, ISSN: 1748-3387

Rathore, N. S. (1974). On a New Systematic Character in Termites, The Microsters. Z. Zool. Syst. Evolutionsforsch Berlin, Vol. 12, pp. 55-76.

Rathore, N. S. (1977). Third Study of Evolution and Systematic Significance of Wing MicroSculpturing in Termites. Micrasters in some Thinotermitidae and Termitidae. Zoologischer Anzeiger, Vol. 198, pp. 298-312, ISSN: 0044-5231

Roonwal, M. L. (1985). Wing Microsculpturing in Termites (Isoptera) under the Scanning Electron Microscope. Zoologischer Anzeiger (Jena), Vol. 215, pp. 219-230, ISSN: 0044-5231

Stevens, M. \& Merilaita, S. (2009). Animal camouflage: current issues and new perspectives. Philosophical Transactions of the Royal Society B-Biological Sciences, Vol. 364, No. 1516 (Feb 2009), pp. 423-427, ISSN_1471-2970

Sun, T.; Feng, L.; Gao, X. \& Jiang, L. (2005a). Bioinspired Surfaces with Special Wettability. Accounts of Chemical Research. Vol. 38, No. 8, (August 2005), pp. 644-652, ISSN: 0001-4842

Sun, M.; Luo, C.; Xu, L.; Ji, H.; Ouyang, Q.; Yu, D. \& Chen, Y. (2005b). Artificial Lotus Leaf by Nanocasting. Langmuir, Vol. 21, No. 19, (August 2005), pp. 8978-8981. ISSN: 0743-7463

Tong, J. Sun, J. Chen, D. \& Zhang, S. (2005). Geometrical Features and Wettability of Dung Beetles and Potential Biomimetic Engineering Applications in Tillage Implements. Soil \& Tillage Research, Vol. 80, No. 1-2, (January 2005), pp. 1-12, ISSN: 0167-1987

Wagner, P.; Neinhuis, C. \& Barthlott, W. (1996). Wettability and Contaminability of Insect Wings as a Function of their Surface Sculptures. Acta Zoologica, Vol. 77, No. 3, (July 1996), pp. 213-225, ISSN: 1463-6395

Wang, S. \& Jiang, L. (2007). Definition of Superhydrophobic States. Advanced Materials, Vol. 19, No. 21, (November 2007), pp. 3423-3424, ISSN: 1521-4095

Wenzel, R. N. (1936). Resistance of Solid Surfaces to Wetting by Water. Industrial Engineering Chemistry, Vol. 28, pp. 988-994, ISSN: 0888-5885

Wong, P. Y. Miaoulis, I. N. Tada, H. \& Mann, S. (1997). In: ASME Fundamentals of Microscale Biothermal Phenomena, American Society of Mechanical Engineers, New York.

Yoshimitsu, Z.; Nakajima, A.; Watanabe, T. \& Hashimoto, K. (2002). Effects of Surface Structure on the Hydrophobicity and Sliding Behavior of Water Droplets. Langmuir, Vol. 18, No. 15, (June 2002), pp. 5818-5822. ISSN: 0743-7463 


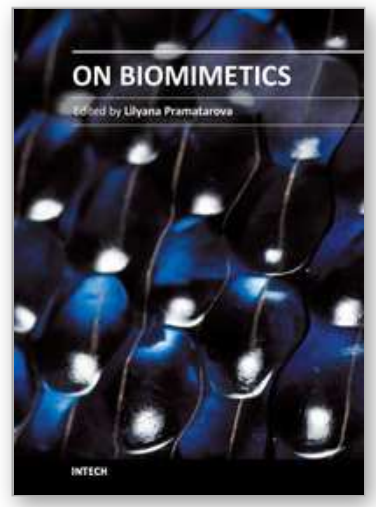

\author{
On Biomimetics \\ Edited by Dr. Lilyana Pramatarova
}

ISBN 978-953-307-271-5

Hard cover, 642 pages

Publisher InTech

Published online 29, August, 2011

Published in print edition August, 2011

Bio-mimicry is fundamental idea â€ How to mimic the Natureâ€TM by various methodologies as well as new ideas or suggestions on the creation of novel materials and functions. This book comprises seven sections on various perspectives of bio-mimicry in our life; Section 1 gives an overview of modeling of biomimetic materials; Section 2 presents a processing and design of biomaterials; Section 3 presents various aspects of design and application of biomimetic polymers and composites are discussed; Section 4 presents a general characterization of biomaterials; Section 5 proposes new examples for biomimetic systems; Section 6 summarizes chapters, concerning cells behavior through mimicry; Section 7 presents various applications of biomimetic materials are presented. Aimed at physicists, chemists and biologists interested in biomineralization, biochemistry, kinetics, solution chemistry. This book is also relevant to engineers and doctors interested in research and construction of biomimetic systems.

\title{
How to reference
}

In order to correctly reference this scholarly work, feel free to copy and paste the following:

Jolanta A. Watson, Hsuan-Ming Hu, Bronwen W. Cribb and Gregory S. Watson (2011). Anti-Wetting on Insect Cuticle - Structuring to Minimise Adhesion and Weight, On Biomimetics, Dr. Lilyana Pramatarova (Ed.), ISBN: 978-953-307-271-5, InTech, Available from: http://www.intechopen.com/books/on-biomimetics/anti-wetting-oninsect-cuticle-structuring-to-minimise-adhesion-and-weight

\section{INTECH}

open science | open minds

\section{InTech Europe}

University Campus STeP Ri

Slavka Krautzeka 83/A

51000 Rijeka, Croatia

Phone: +385 (51) 770447

Fax: +385 (51) 686166

www.intechopen.com

\section{InTech China}

Unit 405, Office Block, Hotel Equatorial Shanghai

No.65, Yan An Road (West), Shanghai, 200040, China

中国上海市延安西路65号上海国际贵都大饭店办公楼405单元

Phone: +86-21-62489820

Fax: $+86-21-62489821$ 
(C) 2011 The Author(s). Licensee IntechOpen. This chapter is distributed under the terms of the Creative Commons Attribution-NonCommercialShareAlike-3.0 License, which permits use, distribution and reproduction for non-commercial purposes, provided the original is properly cited and derivative works building on this content are distributed under the same license. 